\title{
Erratum to: Reversal of Thienopyridine-Induced Platelet Dysfunction Following Desmopressin Administration
}

\author{
Michael Levine • Steve Swenson • Taylor McCormick • \\ Sean O. Henderson • Stephen H. Thomas • \\ Francis S. Markland
}

Published online: 4 June 2014

(C) American College of Medical Toxicology 2013

\section{Erratum to: J. Med. Toxicol.}

$$
\text { DOI 10.1007/s13181-012-0275-6 }
$$

In "Reversal of thienopyridine-induced platelet dysfunction following desmopressin administration" by Levine et al. in the June 2013 issue of Journal of Medical Toxicology, the bottom of the original Fig. 1 erroneously reads "central blood obtained for bleeding time via closed cardiocentesis." It should read "central blood obtained for platelet aggregation studies via closed cardiocentesis."

The correct figure is shown below.

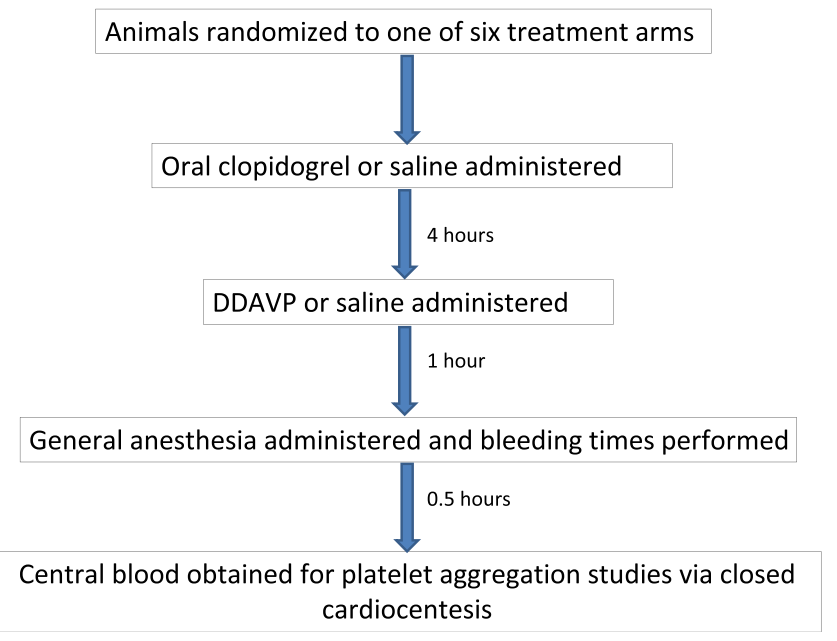

The online version of the original article can be found at http://dx.doi.org/ 10.1007/s13181-012-0275-6.

\section{Levine $(\bowtie)$}

Department of Emergency Medicine, Section of Medical

Toxicology, University of Southern California,

1200 North State Street, Room 1011,

Los Angeles, CA 90033, USA

e-mail: Michael.Levine@bannerhealth.com

S. Swenson · F. S. Markland

Department of Biochemistry and Molecular Biology

and the Norris Comprehensive Cancer Center,

Keck School of Medicine, University of Southern California,

Los Angeles, CA, USA

T. McCormick • S. O. Henderson

Department of Emergency Medicine, University of Southern

California, Los Angeles, CA, USA

\section{S. H. Thomas}

Department of Emergency Medicine, University of Oklahoma

School of Community Medicine, Tulsa, OK, USA 